Review

\title{
Prenatal Testing - What Is It Good For? A Review and Critique
}

\author{
Robert Resta *
}

Retired, Seattle, WA, USA; E-Mail: rgresta@icloud.com

* Correspondence: Robert Resta; E-Mail: rgresta@icloud.com

Academic Editors: Diane Paul and Ilana Löwy

Special Issue: Policy Issues in Prenatal and Neonatal Testing, Counseling, and Decision-Making

OBM Genetics

2021, volume 5 , issue 3

doi:10.21926/obm.genet.2103136
Received: June 22, 2021

Accepted: August 26, 2021

Published: September 01, 2021

\begin{abstract}
The goals of prenatal testing remain controversial and reflect competing interests of public health, patient rights, disability activists, scholars, feminist critics, commercial laboratories, judiciary/legislative trends, and medical science. This paper reviews and critiques the most common justifications of prenatal testing for fetal aneuploidy that have been put forth over the half century of its existence: reducing the medical and economic burden to society of genetic disease through selective abortion, allowing parents to avoid raising a child with disabilities, preventing the suffering associated with chromosomal and genetic disorders, emotional reassurance about the health of the baby, and medical and emotional preparation for the birth of a baby with a disability. Each of these goals has problematic aspects, as do some of the criticisms of these goals. The most striking shortcoming of the justifications for prenatal testing is a dearth of research about potential medical, psychological, or adaptational benefits of prenatal testing, especially for aneuploidy, for babies and families, beyond the option of pregnancy termination.
\end{abstract}

\section{Keywords}

Prenatal testing; prenatal diagnosis; prenatal screening; ethical justification; abortion; costbenefit analysis; disability critique; NIPT

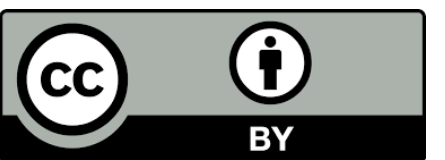

(c) 2021 by the author. This is an open access article distributed under the conditions of the Creative Commons by Attribution License, which permits unrestricted use, distribution, and reproduction in any medium or format, provided the original work is correctly cited. 


\section{Introduction}

The first report of a prenatal diagnosis appeared over a century ago [1] but the modern era of prenatal testing began in the 1960s and early 1970s and was made possible by advances in cell culturing and karyotyping, the introduction of amniocentesis and ultrasonography, and the legal availability of safe abortion [2]. Over the ensuing decades, prenatal testing expanded in scope and, in various forms, is now widely available in many countries. Yet the goals of prenatal testing are not always clear, may rest on questionable assumptions, and are open to ethical debate. In this paper I review and critique the justifications offered for prenatal testing.

\section{Background}

Prenatal diagnosis consists of procedures used to diagnose a condition in an embryo or fetus and commonly include amniocentesis, chorionic villus sampling (CVS), or ultrasonography. Prenatal screening identifies women who are candidates for undergoing prenatal diagnosis because of some factor that puts them at greater risk of having a baby with a chromosomal, genetic, or congenital condition. Examples of prenatal screens include measurement of analytes in maternal serum (AFP, hCG, etc.); analysis of cell-free placental DNA in maternal serum, usually referred to as non-invasive prenatal testing (NIPT); ultrasonography (which can be both a screening and a diagnostic tool, depending on the condition); parental age; family or reproductive history of a child with a genetic or congenital condition; and carrier screening of parents to determine if they carry pathogenic variants of monogenic conditions (which may also take place prior to conception). In this paper, I use the term prenatal testing to generally refer to both prenatal screening and prenatal diagnosis

Prenatal testing has traditionally been centered on the detection of fetal aneuploidy, primarily Down syndrome, trisomy 18 , trisomy 13 , and, to a lesser extent, sex chromosome aneuploidies. Other than maternal age there are no significant risk factors for giving birth to a child with aneuploidy, such as environmental exposures or family history, i.e., it usually comes "out of the blue" (only a very small percentage of babies with Down syndrome is due to a parental balanced chromosomal translocation).

Of the autosomal trisomies, Down syndrome is the most common, the most widely known, straight-forward to diagnose, and associated with intellectual disability, although prognosis is variable and unpredictable and public understanding of the syndrome is poor [3]. It is the only autosomal trisomy associated with significant rates of survival beyond early childhood, and, as such, can be viewed as more of a "public health issue" and a long-term commitment for families compared to the other autosomal aneuploidies [4,5]. People with Down syndrome have a characteristic facial appearance such that the condition is readily apparent, unlike some other conditions such as autism or non-specific developmental disabilities that may have no physical attributes or are obvious only to someone with professional training. This characteristic appearance can add to the perceived stigma of having a child with Down syndrome and for some parents is a narcissistic threat [6]. For many people, Down syndrome is literally the face of intellectual disability [7-9]. For these reasons, Down syndrome has been the critical driver of the prenatal diagnosis engine.

The most common sex chromosome aneuploidies - Turner syndrome, Klinefelter syndrome, XYY, and $X X X$ - are associated with learning disabilities and psychiatric issues. They are not generally associated with significant developmental or physical disabilities to the extent that autosomal 
trisomies generally are. Turner syndrome is associated with a variety of physical findings such as heart defects, streak ovaries, and renal anomalies, but these are not usually life-threatening (although prenatally $~ 99 \%$ of conceptions with Turner syndrome are spontaneously miscarried, typically in the first trimester [10]). Turner syndrome and Klinefelter syndrome are associated with impaired fertility. NIPT can detect sex chromosome aneuplodies, potentially at high rates, but further studies are necessary to more closely evaluate test performance, especially in average risk pregnancies [11].

To be sure, many monogenic and congenital conditions are also identifiable through routine prenatal testing. But individually these other conditions are rare except in select populations as a result of founder mutations, selective evolution, genetic drift, and inbreeding, such as the thalassemias in Cyprus or Tay-Sachs disease among Ashkenazi Jews [12, 13]. They comprise a small portion of all prenatal tests, and, for the most part, are limited to pregnancies where the couple has been identified at higher risk due to family history, or carrier screening for monogenic disorders. Of course, if a woman has had a positive aneuploidy screen and then undergoes a diagnostic test, the fetus may incidentally be tested for a number of conditions beyond aneuploidy [14]. But it was the positive aneuploidy screen that led to the additional diagnostic testing to begin with.

Beyond aneuploidy screening, prenatal diagnosis is also performed when an ultrasound scan detects structural anomalies that are associated with a wide range of causes that often require microarrays or genomic testing for detection $[15,16]$. Some of these conditions can impact pregnancy management decisions beyond termination [17]. The scope of routine prenatal testing will expand if routine wide-scale prenatal genome analysis becomes feasible, but for a variety of technical, economic, and social reasons it seems unlikely in the near future that all pregnant women will be offered prenatal testing with sequencing of a large portion of the fetal genome.

In the 1970s and early 1980s, amniocentesis and, eventually, CVS were offered only to a very limited number of women deemed to be at higher risk of having a baby with an aneuploidy due to maternal age, if ultrasound detected fetal problems, or, sometimes, family history. From the 1980s to the 2000s, maternal serum screening for fetal aneuploidy using various combinations of analytes such as hCG, AFP, and estriol, along with first and second trimester sonography, became incorporated into prenatal testing and were offered to a wider range of women other than only those 35 and older. These technologies had better sensitivity in detecting aneuploidy than maternal age alone, but had fairly high false positive rates and low positive predictive values [18]. Noninvasive prenatal testing (NIPT) using placental DNA circulating in maternal blood to screen for aneuploidy and other conditions entered into clinical practice in the second decade of the $21^{\text {st }}$ century[2]. NIPT can detect well over $90 \%$ of aneuploid pregnancies with a much lower false positive rate, though the detection rate and positive predictive value vary with maternal age and other factors [19].

In many High Income Countries prenatal testing is no longer a niche service offered to a select percentage of "eligible" women [20]. Ultrasonography, maternal serum screening, and NIPT have become routinized into pregnancy care, although some countries do not offer all of these modalities to all pregnant women $[20,21]$. The high detection rate of NIPT for fetal aneuploidy, along with the high termination rates of affected pregnancies in select populations, has raised concerns among disability rights activists and disease-advocacy groups about a potential dramatic reduction in the birth of people with Down syndrome [22]. And, because prenatal testing is more commonly utlized by upper income women, a disproportionate number of babies with Down syndrome are born to 
poorer women who may not have the financial, medical, and societal resources to care for children with physical and cognitive disabilites [5].

\section{Why Do Prenatal Testing?}

Prenatal testing has at least 5 stated goals:

1) Preventing the economic and medical burden of genetic disease to society through selective abortion.

2) Abortion of fetuses diagnosed with aneuploidy and other conditions so parents can choose to avoid raising a child with a disability. This goal overlaps with the above goal of prevention in that the outcome may be the same but the intent is different in viewing the decisions through the lens of the impact on the family rather than through a public health perspective.

3) Avoiding suffering associated with genetic disease in the future child.

4) Provide reassurance to parents about the health of their baby when results are normal.

5) Emotional and medical preparation for the birth of a child to improve medical outcomes for the child and psychological adaptation of the parents to raising children with cognitive and physical disabilities.

Below I critique each of these goals and examine some of the criticisms of those goals.

\subsection{Preventing Genetic Disease: A Public Health Perspective}

Prenatal testing and abortion of affected fetuses can result in the prevention of certain chromosomal, genetic, and congenital conditions. The net effect is the avoidance of certain disabilities as well as reducing national health costs.

Genetic counselors are usually reluctant to make the link between prenatal diagnosis and the prevention of genetic disease through abortion, probably to distance themselves from eugenic criticisms and to avoid contentious abortion debates [23]. But from the start, amniocentesis was offered with the often explicit understanding that, although it should unquestionably be a free choice of parents, most women would choose to terminate a pregnancy in which a trisomy or other serious condition has been identified, as this quote from a 1970s paper illustrates:

We are less certain about the balance and costs [of amniocentesis] at current rates of screening the whole pregnant population. But is a detailed estimate of the costs required? The lifelong care of severely retarded persons is so burdensome in almost every human dimension that no preventive program is likely to outweigh the burden [24].

When amniocentesis was introduced into obstetric care in the 1970s in the US and the UK, it was often stated that the primary justification for using a specific age cut-off, typically about age 35, was that by the time a woman was in her mid-30s, the probability of aneuploidy exceeded the procedure-related loss rate of amniocentesis. In fact, a closer examination of the literature from that time reveals that age cut-offs were based more on economic rather than medical criteria, i.e., the age at which the cost of prenatal testing was less than the projected economic cost to society of caring for individuals with Down syndrome [25]. Prenatal testing, at least in the US and the UK, was predicated on the basis of economic cost-benefit analysis and the belief that most women who underwent testing would not want to raise a child with a significant disability. This occurred during a time, particularly in post World War II America, when prevention of all types of disability was a widely accepted goal of medicine and society [26]. 
In the United States in the late 1970s, about 5\% of all pregancies occurred to women 35 and older, though in practice amniocentesis was utilized by a much lower percentage of these "eligible" pregnant women $[27,28]$. But even in the theoretical scenario wherein all of the $\sim 5 \%$ of eligible US women had undergone amniocentesis at that time and chose to terminate all pregancies with Down syndrome, this would have avoided the birth of about $20 \%$ of all babies with Down syndrome [27]. Thus, although critics in the 1980s raised ethical concerns about the eugenic implications of amniocentesis for people with disabilities [29, 30], in practice, given the small percentage of women who actually underwent amniocentesis at that time, prenatal diagnosis did not represent a significant existential threat to the population of people with Down syndrome. The goal of prenatal testing seemed to be preventing just enough births of babies with Down syndrome to save money but with no stated intention of eliminating Down syndrome altogether, the above comments of Stein et al. not withstanding.

Cost-savings may play a less prominent role in justifying prenatal diagnosis today but it has not disappeared, as this opening sentence from a recent article by Italian authors illustrates:

The purpose of prenatal diagnosis is to reduce both the incidence and prevalence of inherited conditions, which have a strong impact on both the psychological and economic aspects of people's lives, whether the ill ones or their parents, as well as being an economic burden for national health systems [31].

In addition, several articles about prenatal testing published over the last few years from China, the UK, Belgium, the US, Thailand, and Canada have included cost/benefit analysis as a justification for aneuploidy screening in their analyses and/or discussions [32-38].

In practice, the majority of women who undergo prenatal testing in most, but not all, western European countries, the US, Canada, and Australia choose to terminate a pregnancy in which an autosomal trisomy has been diagnosed. To some extent termination reported rates are biased upwards because many women who would not consider undergoing a termination may be less likely to undergo prenatal testing to begin with. Termination rates vary geographically, over time, with attitudes toward disability, with religious beliefs, by socioeconomic status, the availability of abortion, the severity of the condition, and other factors. A 2012 literature review of termination following a diagnosis of Down syndrome in the US found an average termination rate of $67 \%$ (range, 50-85\%) [39]. Earlier studies based in the US and abroad had found termination rates for Down syndrome to be greater than $90 \%$ [40]. The termination rate for spina bifida has been reported as $63 \%$ (range, 31-97\%) and 83\% for anencephaly (range, 59\%-100\%) [41]. However, the pregnacy termination rate after a autosomal aneuploidy diagnosis is highly variable geographically and among select groups, and in some regions has dropped over time [42-44].

The termination rates for the sex chromosome aneuploidies are also highly variable between and within countries but are generally lower than the termination rates for autosomal aneuploidies, with the exception of Turner syndrome. For example, a survey over of 21 French cytogenetic laboratories over a 22 year period found that the termination rate for Turner syndrome was about $90 \%$ in the earlier years but $80 \%$ more recently [45]. A Welsh survey of pregnancies with Turner syndrome found a termination rate of $66 \%$ over 10 years. A Chinese study of sex chromosome aneuploidies detected through NIPT screening reported termination rates of $85 \%, 73 \%, 20 \%$, and $10 \%$ for Turner syndrome, Klinefelter syndrome, XXX, and XYY, respectively [46]. In a study from Hong Kong, the overall termination rate for sex chromsome aneuploidies was $55.6 \%$, with specific rates of $91.7 \%, 48.0 \%, 23.4 \%$, and $4.8 \%$, for $45, X, 47, X X Y, 47, X X X, 47, X Y Y$, respectively [47]. The 
EUROCAT network reported termination rates for sex chromosome trisomies (de facto excluding Turner syndrome) that ranged from $13 \%-67 \%$, with average rates across countries of about $30-40 \%$ for $X X X, X X Y$, and XYY combined [48].

To fully appreciate the impact of these termination rates on the incidence of Down syndome and other aneuploidies, it is important to remember that many women do not undergo diagnostic testing or screening. Consequently, these percentages do not reflect the percentage of all pregnancies with these conditions, only those undergoing diagnostic testing. Thus, many babies with Down syndrome are still being born. While the incidence of Down syndrome at birth has decreased in the US and Europe, due primarily to prenatal diagnosis and selective termination, this decrease has been partially offset by a parallel increase in the population frequency of Down syndrome across the age spectrum as the result of more pregnancies to woman 35 and older, combined with longer survival of people with Down syndrome due to improvements in their medical care, increasing social stigmatization of, and increasing difficulty in obtaining, abortion $[5,42,44$, 49-51]. Prenatal testing can result in a significantly lower occurrence of Down syndrome in any given country or region but it currently does not pose an existential threat to the frequency of Down syndrome on a global level.

The economic benefit to society of avoiding births with Down syndrome is ethically complex and difficult to justify today, as several commentators have noted [20,52-54]. Most of the medical costs due to Down syndrome occur in the first year of life when surgeries are most likely to be performed [55]. The costs are roughly on par with the medical costs related to the obstetric and neonatal complications resulting from Assisted Reproductive Technologies, such as cesarean section, low birth weight, and prematurity [56]. Many people with Down syndrome and other conditions now lead more fulfilling and economically productive lives, due in part to the efforts of advocates to provide better education, medical care, job opportunities, social support, and social acceptance for people with disabilities $[5,42]$. It is likely that in countries where they are given these advantages, people with Down syndrome are far less of an economic "drain" on society than other more common and chronic conditions such as diabetes, stroke, or lung and other diseases resulting from tobacco use. And, on a fundamental ethical level, economic cost-benefit analysis deprives people of their essential humanity and reduces their value as human beings to their financial worth. Prenatal screening saves money - but at what cost?

That being said, prenatal testing should be conducted using the most cost-efficient technology and screening strategies that are feasible for any given testing program. Nor is it ethically objectionable if prenatal testing eventually proves to save money incidental to avoiding some births of children with disabilities, as long as the cost-savings is not the fundamental aim of the program.

For trisomy 18 and trisomy 13, the societal economic impact is fairly small, given that the conditions are uncommon and have a high - but not absolute - mortality rate in the first year of life [57]. Of course, the economic impact on individual families can be high, depending on the availaiblity and extent of health insurance coverage and social support [58].

Given the lesser physical and cognitive impact of the sex chromosomal aneuploidies, it is even more difficult to suggest that cost-benefit savings and disability avoidance can justify prenatal screening for these conditions.

Critics of prenatal testing, particularly scholars engaged in disability studies and advocates for people with disabilities, have asserted that the very offer of prenatal screening is discriminatory because it devalues the lives of people with disabilities and, because the high abortion rates, 
amounts to a modern form of eugenics [29, 30,59]. This is not to imply that all people with disabilities, their families, supporters, and scholars condemn prenatal testing. As in the general population, this group includes a wide range of opinions and reproductive choices and the voices of outspoken critics do not necessarily reflect the varied views within this population $[44,60]$.

This tension among viewpoints remains contentious and has resulted in some uneasy and unusual alliances between disability activists and pro-life interests [61]. These alliances have produced some legislative headway. Some states in the US have passed legislation banning abortions for the specific reason of a diagnosis of Down syndrome [62]. Similar trends have been seen in Europe [63]. These laws may have been passed in part as a general strategy to make any abortion unavailable, rather than an effort to protect people with Down syndrome per se.

Limiting abortion for this specific indication further erodes the abortion options for all women. If abortion is available, it should be an option for all women, regardless of their motivations. Having an abortion because it may not be the best time in one's life to have a baby or because a woman is in an abusive realtionship are no more or less ethically compelling reasons than wanting to avoid raising a child with disabilities. In addition, many anti-abortion groups are also ultra-conservative opponents of homosexuality, transgender people, and even contraception. By aligning with these groups, disability critics and disease advocacy groups wind up implicitly supporting a wide range of ethically questionable and unrelated policies.

Many states and countries that pass legislation to impose limits on termination are those that offer the least amount of social and medical services to families, especially lower income families. Along those same lines, many anti-abortion supporters are opposed to government programs that offer economic, medical, and other support to poor women [63-65]. Thus, from an ethical and social justice standpoint, it is difficult to justify opposition to abortion without a concommitantly passionate support of governmental and other support to make sure that all children have adequate medical, educational, nutrional, and economic resources.

\subsection{Avoiding Suffering}

Some parents choose to undergo prenatal testing in order to avoid future suffering that a child with disabilities might experience $[66,67]$. Babies with autosomal trisomies often have significant physical impairments that may or not be treatable, such as serious heart defects, and often need to undergo multiple medical procedures as infants and children (these are less common among children with sex chromosome aneuploidies). Some rare conditions can impose significant prenatal suffering for fetuses, such as some severe skeletal dysplasias that can cause in utero skeletal breaks, severe genodermatoses that can cause prenatal blistering and skin loss, or limb-body wall defect characterized by multiple major malformations.

What is unclear, except in some very serious conditions, is just how much suffering is experienced by people with many chromosomal genetic and congenital conditions. It is very difficult for anyone to imagine life with a chromosomal, congenital, or genetic condition and, conversely, it is difficult for people with a congenital or genetic condition to imagine what life is like without the condition, especially if the condition involves cognitive impairment [68]. Furthermore, people with disabilities who participate in research tend to be higher functioning, and thus not necessarily representative of all people with the condition. This limitation is particularly critical in Down syndrome, where the impairment can range from significant to moderate. Overall, though, people with Down syndrome 
and their families generally feel like they are not experiencing constant suffering or leading uniformly unhappy lives, while still acknowledging the associated medical, familial, and social challenges [69-73].

For infant with other autosomal trisomies, while not downplaying the trials of multiple surgeries or tube feeding for adequate nutrition, it is difficult to know just how much suffering they are experiencing when they are not undergoing surgery or other treatment. At least some families find that having a child with trisomy 18 or 13 is an overall positive experience and for some children with these conditions surgery may extend their lives [74-77].

Children and adults with sex chromosome trisomies do not have a particularly high incidence of physical defects that require extensive medical intervention. Although social and psychological problems are common among people with the sex chromosome trisomies, overall quality of life is generally positive [78-80]. Girls and women with Turner syndrome may need surgery for heart defects and can have emotional, psychological, and social difficulties as a result of their condition, but they do not seem to be experiencing significant physical suffering [81]. Turner syndrome and Klinefelter syndrome are associated with impaired fertility, which, for some individuals, may cause emotional suffering.

People with monogenic conditions and non-trisomic conditions have varying perspectives on their conditions and on prenatal testing. Some view genetic impairment as part of their identity and support policies of removing physical and social barriers and improving clinician knowledge of their conditions over prenatal testing while others report more negative experiences with their conditions $[82,83]$.

Ultimately, with some exceptions, because it is difficult to know how much suffering is experienced by people with most chromosomal, monogenic, and congenital conditions, it is hard to know what moral weight to give to it as a justification for prenatal testing. How can we know if prenatal testing reduces suffering if we don't know if people with any given condition actually suffer or to what extent?

\subsection{Supporting Parental Choices to Avoid Raising a Child with a Disability}

Advocates of prenatal testing have argued that the ethos of testing has shifted from the public health perspective of cost-savings and disability avoidance to permitting parents to make choices about whether to continue - or not - a pregnancy in which a fetus has been diagnosed with Down syndrome or other condition [84]. Abortion following prenatal diagnosis allows at least some women to make difficult and highly situated choices about continuing a pregnancy and whether to raise a child with disabilities. While respecting the essential humanity of people with disabilities, the impact of raising a child with a significant disability can vary with factors such as socioeconomic status, the nature of a woman's relationship with her partner if she has one, parental age, parental health, familial and social support, and the availability of societal resources. Essentially, some parents are better situated than others to care for and raise a child with physical and/or cognitive disabilities. In a less than perfect world, this justification for prenatal testing carries significant ethical weight.

Critics of this view counter that whatever the intentions of parents, the net effect is still eugenic because the net result is a reduction in the number of people with disabilities, even if it not statesponsored or otherwise intended as such. But this labelling amounts to name calling, rather than 
acknowledging the challenging, resource-poor situations parents can find themselves in. There is no evidence that the availability of abortion is associated with more negative attitudes toward people with disabilities or a reduction in available resources for them. In fact, generally speaking, the opposite trend appears to be true [63].

But as I discuss below, while this is a compelling reason to offer prenatal testing, it would be on firmer ethical ground if, in addition to allowing parents to make difficult choices, it could be shown that prenatal testing also improves medical and other outcomes for people with disabilities and their families.

\subsection{Reassurance about the Health of the Fetus}

A common reason to undergo prenatal screening is reassurance about the health of the fetus, at least as far as aneuploidy is concerned $[85,86]$. While this may be true, it is also true that the very offer of prenatal screening itself generates anxieties that lead to the need for reassurance. In a world where prenatal screening was not available, pregnant women would likely have typical generalized concerns about the physical and cognitive health of their babies. But it seems unlikely that most pregnant women would focus their anxiety specifically on Down syndrome unless the possibility of the baby having Down syndrome had been raised by their care providers or a parent has had personal experience with the condition. Even for a 35-year-old woman, the chance of giving birth to a baby with Down syndrome is less than $1 \%$. As genetic counselors know, re-framing can be a powerful counseling strategy. If a 35-year-old woman was instead told that there is over a $99 \%$ chance that at her age she will not have a baby with Down syndrome, she would likely find that a very reassuring statistic and may not even consider prenatal testing. Prenatal testing can thus be viewed as a self-fulfilling prophecy - it's offer creates anxiety about a specific relatively uncommon problem in the baby and undergoing prenatal testing can potentially alleviate that anxiety.

In addition, aneuploidy is only one of many problems a baby may have, and overall makes up only a small portion of all genetic and congenital conditions. A normal prenatal test leaves unanswered the status of a whole host of conditions that can affect a child - cerebral palsy, prematurity, low birth weight, most forms of cognitive impairment, most genetic conditions, and autism, to name just a few. In practice, prenatal screening offers only very limited reassurance. If prenatal testing expands to include genomic testing, the number of conditions detectable will increase, and in that future scenario parents may justifiably get greater reassurance from prenatal testing.

This narrow reassurance is glossed over in the online advertising of many prenatal testing laboratories. Their websites usually present graphics of beautiful, smiling, healthy babies alongside their equally beautiful and smiling parents, and broad statements about the value of the test and patient testimonials, as these quotes taken from 3 different lab websites illustrate:

...the most reliable way of non-invasively assessing a baby's health... (https://www.natera.com/womens-health/panorama-nipt-prenatal-screening/patients/, accessed 6/5/2021)

NIPT is incredible. It offers you so much information... (https://www.illumina.com/clinical/reproductive-genetic-health/nipt.html, accessed 6/5/2021)

Taking it has helped me sleep better because getting answers is a huge relief. (https://myriadwomenshealth.com/patient-prequel/, accessed 6/5/2021) 
THERE'S POWER IN BEING PREPARED (Upper case in original); (https://myriadwomenshealth.com/patient-prequel/, accessed 6/5/2021)

Commercial laboratories have recognized that prenatal testing can be a significant source of revenue $[87,88]$. By one estimate, the worldwide market for NIPT is expected to be at least eleven billion dollars (US) by the year 2030 [89]. To appeal to the market of pregnant women, this advertising emphasizes the reassurance aspect of prenatal testing, while not making it clear just how much reassurance women should receive from their products [90]. Notably, the websites rarely mention abortion and usually do not prominently display photographs of babies with Down syndrome or trisomy 18 . Presumably a mention of abortion or a photograph of a child with Down syndrome would not reinforce a message of reassurance or help sell a test.

\subsection{Medical and Emotional Preparation}

A common reason for women to undergo prenatal testing is to have emotional, psychological, and medical preparation if the baby has Down syndrome or other condition [91], a justification I frequently heard during my 22 years working as a genetic counselor in a busy prenatal diagnosis clinic. Interestingly, one study reported that most women who chose to continue a pregnancy with Down syndrome experienced an increase in anxiety during the pregnancy, although many women said they if they could do it over, they would still choose to undergo prenatal diagnosis again [92].

In 2017, participants from a variety of specialties such as obstetrics, maternal fetal medicine, genetics, and other prenatal testing experts met to develop a framework for introducing new prenatal tests, criteria for providing genetic counseling and consent, and guidelines for the use of existing prenatal genetic tests. A summary of the workshop's findings in terms of the purpose of prenatal testing suggested that improving fetal and maternal outcomes (without defining what constitutes an improved outcome) should be a primary goal of prenatal testing:

The participants of this workshop were in agreement that the goal of prenatal genetic testing should be focused on improving outcomes for women and families [84].

However, the workshop summary also reported that it was not clear that prenatal diagnosis of most conditions had measurable benefit:

For many genetic disorders, more information will not change the outcome directly [84].

There is some limited evidence that prenatal diagnosis can improve fetal outcomes and prevent some maternal complications. Some fetal anomalies are associated with complications of labor and delivery such as shoulder dystocia, c-section, and hypertension [93, 94]. For a few uncommon conditions, some infants may derive medical benefit, e.g., gastroschisis, isolated low lumbar meningomyelocele, some cases of isolated diaphragmatic hernia, all conditions usually detected by ultrasonography and maternal serum screening.

A majority of babies with Down syndrome require intensive care as newborns, usually due to structural anomalies such as heart defects or duodenal atresia [95, 96]. Thus, there is reason to believe that prenatal diagnosis of Down syndrome could result in medical benefit for some babies if the delivery occurs in a hospital with a Neonatal Intensive Care Unit (NICU). But tellingly, almost no studies have been performed on babies with Down syndrome or any autosomal aneuploidy diagnosed prenatally and carried to term to determine whether they have better medical outcomes than those diagnosed at birth. It is also unclear what emotional benefits families obtain from foreknowledge of an affected child via prenatal testing. While many women undergo testing for 
emotional preparation, there is no proven measurable and concrete benefit [91]. Such empirical data would be very helpful to women who are trying to decide whether to undergo prenatal testing, particularly women who would not consider abortion.

What is particularly striking is that even though prenatal testing, particularly for aneuploidies, has been available for more than half a century, there has been very little research on direct measurable medical, psychological, adaptational, or familial benefits for affected children and their families [97]. Why hasn't the research been done? This paucity of such research reinforces the criticism that the abortion of affected fetuses is, from a medical and public health perspective, still the primary reason for the offer of prenatal diagnosis.

Beyond aneuploidy, genomic testing can be helpful in diagnosing conditions that may influence obstetric and neonatal management, especially when an ultrasound has revealed fetal anomalies [17, 98-101]. In addition, if prenatal genomic testing yields a positive diagnosis, neonatal management decisions could be made immediately at birth, rather than having to wait for test results after delivery, which could take several weeks. However, these studies typically consist of small case series with no matching controls. In addition, genomic testing often yields variants of uncertain clinical significance, which can create greater decision-making dilemmas for parents and add to their anxieties [102].

Another potential advantage of prenatal diagnosis for women who would not or cannot consider pregnancy termination is in situations in which the baby will be born with a condition associated with very poor neonatal survival, such as anencephaly, triploidy, or if genomic testing yields a diagnosis of severe monogenic condition. Different families may have different preferences and values regarding the types of medical care the baby should receive at birth, such as palliative care or aggressive intervention with surgery and placement in a NICU. Hospitals and care providers may have different policies about what they consider appropriate care in these situations. Prenatal knowledge of a condition could allow a family to choose a delivery location and care providers who will respect the family's wishes as much as is legally possible [99].

\section{Conclusion}

Prenatal testing can no longer be ethically or practically justified by the economic benefits to society. Offering prenatal testing to reduce anxiety is also a weak justification, other than situations where couples have a reproductive or family history of a specific disease, since the offer of testing itself plays a major role in engendering the specific anxieties said to be alleviated by prenatal testing, and because prenatal testing covers only a very limited number of disabilities and conditions. It is also unclear just how much suffering is experienced by individuals with most chromosomal, genetic, and congenital disorders and thus it is hard to know to what extent avoiding a birth of a child with such a condition avoids suffering.

Two compelling reasons for offering prenatal testing are that it allows parents to make the extraordinarily difficult and personal choice about whether to raise a child with disabilities and, if they choose to carry the pregnancy to term, to have medical and emotional preparation for caring for a child with disabilities. Unfortunately, almost no research has been conducted to either prove or disprove that prenatal testing actually does improve outcomes for affected children or their families, particularly for chromosomal conditions. In order for routine prenatal testing to be justifiable in the future, there is a pressing need to conduct short and long term research on a large 
scale to determine what benefits prenatal testing offers, if any, beyond pregnancy termination, and for which conditions. Women who are trying to make a choice about whether to undergo prenatal testing should have knowledge about all of its potential benefits and downsides. Prenatal testing can create significant anxiety and there is a possibility that women may eventually have to undergo a diagnostic procedure that carries a small but real risk of fetal loss. If there is no measurable medical or other benefit to prenatal diagnosis of Down syndrome other than termination of pregnancy, then parents can make a better decision that is more consistent with their personal beliefs, desires, and specific situations.

From a social justice standpoint, people with disabilities and their families should also obtain some benefit from prenatal testing, beyond the option of pregnancy termination. If it can be demonstrated that people with disabilities or their families have better outcomes as a result of undergoing prenatal testing, if everyone benefits regardless of individual parent's choices, then prenatal testing stands on firmer ethical ground.

In some - but by no means all - observant Jewish communities, the decision about pregnancy termination following prenatal diagnosis is made by rabbis, after considering the woman's unique circumstances. At least for this population, it shifts the responsibility for decision making from pregnant women to the rabbis [103]. But for many women around the world the choice of whether to continue a pregnancy is a false one because many women do not have access to abortion as the result of economic, social, legislative, familial, or religious factors. Women need to have unrestricted economic and physical access to safe, legal abortion and should be available to all women, regardless of the reason they choose to terminate a pregnancy. Limits on abortion for specific reasons, such as Down syndrome, will only serve as a step to put further restrictions on all abortions and other aspects of people's reproductive and sexual choices.

Presently, most professional societies and national health services recommend that NIPT be used to screen only for aneuploidy, though the tests offered by some laboratories include a few microdeletion syndromes. In the future, in addition to aneuploidy screening, prenatal testing will likely expand to routinely include more extensive coverage of the genome, and not just in a higher risk pregnancies. This could have the potential to diagnose more conditions that might alter pregnancy and neonatal management, improve the medical and developmental outlook for the child, and provide the family with psychological and adaptational benefits. Thus, in addition to studying the technical aspects of expanded prenatal genomic testing such as validity and accuracy, there should be simultaneous research into the impact and outcomes for the child and family. Furthermore, routine prenatal genomic testing will raise legitimate questions about negative eugenic implications. Although developed in the context of reproductive carrier screening, the recommendations of Dive and Newson [104] can serve as a framework for considering the incorporation of genetic conditions into a prenatal screening program. This will ensure that the greatest number of people will reap the benefits of prenatal genomic testing.

\section{Author Contributions}

The author did all the research work of this study.

\section{Funding}

No funding was used to support this work. 


\section{Competing Interests}

The author declares that no competing interests exist.

\section{References}

1. Resta R. Case's case: The earliest report of a prenatal diagnosis of a fetal abnormality. ACOG Clin Rev. 2001; 6: 14-16.

2. Löwy I. Imperfect pregnancies: A history of birth defects and prenatal diagnosis. Baltimore, Maryland, USA: Johns Hopkins University Press; 2017.

3. Levis DM, Harris S, Whitehead N, Moultrie R, Duwe K, Rasmussen SA. Women's knowledge, attitudes, and beliefs about Down syndrome: A qualitative research study. Am J Med Genet A. 2012; 158A: 1355-1362.

4. Meyer RE, Liu G, Gilboa SM, Ethen MK, Aylsworth AS, Powell CM, et al. Survival of children with trisomy 13 and trisomy 18: A multi-state population-based study. Am J Med Genet A. 2015; 170: 825-837.

5. de Graaf G, Buckley F, Dever J, Skotko BG. Estimation of live birth and population prevalence of Down syndrome in nine U.S. states. Am J Med Genet A. 2017; 173: 2710-2719.

6. Jain R, Thomasma DC, Ragas R. Down syndrome: Still a social stigma. Am J Perinatol. 2002; 19 : 99-108.

7. Serafica FC. Persons with down syndrome: Facial characteristics, self- and other-perception, and social acceptance. In: Craniofacial anomalies: Psychological perspectives. New York: Springer; 1995. p. 201-232.

8. Suziedelis AK. Adding burden to burden: Cosmetic surgery for children with down syndrome. Virtual Mentor. 2006; 8: 538-540.

9. Michael Al, Jarrett OO. Parental views on plastic surgery for Down syndrome: An African perspective. Pan Afr Med J. 2019; 32: 207.

10. Hook EB, Warburton D. Turner syndrome revisited: Review of new data supports the hypothesis that all viable $45, X$ cases are cryptic mosaics with a rescue cell line, implying an origin by mitotic loss. Hum Genet. 2014; 133: 417-424.

11. Soukkhaphone B, Lindsay C, Langlois S, Little J, Rousseau F, Reinharz D. Non-invasive prenatal testing for the prenatal screening of sex chromosome aneuploidies: A systematic review and meta-analysis of diagnostic test accuracy studies. Mol Genet Genomic Med. 2021; 9: e1654.

12. Cowan RS. Heredity and hope: The case for genetic screening. Cambridge, Massachusetts: Harvard University Press; 2009.

13. Sutton VR. Tay-Sachs disease screening and counseling families at risk for metabolic disease. Obstet Gynecol Clin North Am. 2002; 29: 287-296.

14. Luo $Y, H u H$, Jiang L, Ma Y, Zhang R, Xu J, et al. A retrospective analysis the clinic data and followup of non-invasive prenatal test in detection of fetal chromosomal aneuploidy in more than 40,000 cases in a single prenatal diagnosis center. Eur J Med Genet. 2020; 63: 104001.

15. Lord J, McMullan DJ, Eberhardt RY, Rinck G, Hamilton SJ, Quinlan-Jones E, et al. Prenatal exome sequencing analysis in fetal structural anomalies detected by ultrasonography (PAGE): A cohort study. Lancet. 2019; 393: 747-757.

16. Mone F, O'Connor C, Hamilton S, Quinlan-Jones E, Allen S, Marton T, et al. Evolution of a prenatal genetic clinic-A 10-year cohort study. Prenat Diagn. 2020; 40: 618-625. 
17. Dempsey E, Haworth A, Ive L, Dubis R, Savage H, Serra E, et al. A report on the impact of rapid prenatal exome sequencing on the clinical management of 52 ongoing pregnancies: $A$ retrospective review. BJOG. 2021; 128: 1012-1019.

18. Ball RH, Caughey AB, Malone FD, Nyberg DA, Comstock CH, Saade GR, et al. First- and secondtrimester evaluation of risk for Down syndrome. Obstet Gynecol. 2007; 110: 10-17.

19. Badeau M, Lindsay C, Blais J, Nshimyumukiza L, Takwoingi Y, Langlois S, et al. Genomics-based non-invasive prenatal testing for detection of fetal chromosomal aneuploidy in pregnant women. Cochrane Database Syst Rev. 2017; 11. doi: 10.1002/14651858.CD011767.pub2.

20. Ravitsky V. The shifting landscape of prenatal testing: Between reproductive autonomy and public health. Hastings Cent Rep. 2017; 47: S34-S40.

21. Gadsboll K, Petersen OB, Gatinois V, Strange H, Jacobsson B, Wapner R, et al. Current use of noninvasive prenatal testing in Europe, Australia and the USA: A graphical presentation. Acta Obstet Gynecol Scand. 2020; 99: 722-730.

22. Leach $M$. What are we losing if Down syndrome disappears? [Internet]. Down Syndrome Prenatal Testing; 2013. Available from: http://www.downsyndromeprenataltesting.com/whatare-we-losing-if-down-syndrome-disappears/.

23. Stoll K. Bob has retired. What are the Resta us going to do now? [Internet]. The DNA Exchange; 2021. Available from: https://thednaexchange.com/2021/02/08/bob-has-retired-what-arethe-resta-us-going-to-do-now/\#comments.

24. Stein Z, Susser M, Guterman AV. Screening programme for prevention of Down's syndrome. Lancet. 1973; 301: 305-310.

25. Resta RG. Historical aspects of genetic counseling: Why was maternal age 35 chosen as the cutoff for offering amniocentesis? Med Secoli. 2002; 14: 793-811.

26. Hogan AJ. Life histories of genetic disease: Patterns and prevention in postwar medical genetics. Baltimore, Maryland: Johns Hopkins University Press; 2016.

27. Resta RG. Changing demographics of advanced maternal age (AMA) and the impact on the predicted incidence of Down syndrome in the United States: Implications for prenatal screening and genetic counseling. Am J Med Genet A. 2005; 133A: 31-36.

28. Luthy DA, Emanuel I, Hoehn H, Hall JG, Powers EK. Prenatal genetic diagnosis and elective abortion in women over 35: Utilization and relative impact on the birth prevalence of Down syndrome in Washington State. Am J Med Genet. 1980; 7: 375-381.

29. Parens $E$, Asch A. Disability rights critique of prenatal genetic testing: Reflections and recommendations. Ment Retard Dev Disabil Res Rev. 2003; 9: 40-47.

30. McDonough P. Congenital disability and medical research: The development of amniocentesis. Women Health. 1990; 16: 137-153.

31. Carbone L, Cariati F, Sarno L, Conforti A, Bagnulo F, Strina I, et al. Non-invasive prenatal testing: Current perspectives and future challenges. Genes. 2021; 12: 15.

32. Chen Y, Qian X, Zhang J, Li J, Chu A, Schweitzer SO. Preliminary study into the economic burden of Down syndrome in China. Birth Defects Res A Clin Mol Teratol. 2008; 82: 25-33.

33. Cuckle $H$, Benn P, Pergament E. Maternal cfDNA screening for Down syndrome--a cost sensitivity analysis. Prenat Diagn. 2013; 33: 636-642.

34. Neyt M, Hulstaert F, Gyselaers W. Introducing the non-invasive prenatal test for trisomy 21 in Belgium: A cost-consequences analysis. BMJ Open. 2014; 4: e005922. 
35. Walker BS, Nelson RE, Jackson BR, Grenache DG, Ashwood ER, Schmidt RL. A cost-effectiveness analysis of first trimester non-invasive prenatal screening for fetal trisomies in the United States. PLoS One. 2015; 10: e0131402.

36. Wanapirak C, Buddhawongsa P, Himakalasa W, Sarnwong A, Tongsong T. Fetal Down syndrome screening models for developing countries; Part II: Cost-benefit analysis. BMC Health Serv Res. 2019; 19: 1-9.

37. Zhang W, Mohammadi T, Sou J, Anis AH. Cost-effectiveness of prenatal screening and diagnostic strategies for Down syndrome: A microsimulation modeling analysis. PLoS One. 2019; 14: e0225281.

38. Fairbrother G, Burigo J, Sharon T, Song K. Prenatal screening for fetal aneuploidies with cellfree DNA in the general pregnancy population: A cost-effectiveness analysis. J Matern Fetal Neonatal Med. 2016; 29: 1160-1164.

39. Natoli JL, Ackerman DL, McDermott S, Edwards JG. Prenatal diagnosis of Down syndrome: A systematic review of termination rates (1995-2011). Prenat Diagn. 2012; 32: 142-153.

40. Mansfield C, Hopfer S, Marteau TM. Termination rates after prenatal diagnosis of Down syndrome, spina bifida, anencephaly, and Turner and Klinefelter syndromes: A systematic literature review. Prenat Diagn. 1999; 19: 808-812.

41. Johnson CY, Honein MA, Flanders WD, Howards PP, Oakley GP, Rasmussen SA. Pregnancy termination following prenatal diagnosis of anencephaly or spina bifida: A systematic review of the literature. Birth Defects Res A Clin Mol Teratol. 2012; 94: 857-863.

42. de Graaf G, Buckley F, Skotko BG. Estimation of the number of people with Down syndrome in Europe. Eur J Hum Genet. 2021; 29: 402-410.

43. Jacobs M, Cooper SA, McGowan R, Nelson SM, Pell JP. Pregnancy outcome following prenatal diagnosis of chromosomal anomaly: A record linkage study of 26,261 pregnancies. PLoS One. 2016; 11: e0166909.

44. Paul DB, Löwy I. On objectivity in prenatal genetic care. OBM Genetics. 2018; 2: 022.

45. Gruchy N, Vialard F, Blondeel E, Le Meur N, Joly-Helas G, Chambon P, et al. Pregnancy outcomes of prenatally diagnosed Turner syndrome: A French multicenter retrospective study including a series of 975 cases. Prenat Diagn. 2014; 34: 1133-1138.

46. Lu X, Wang C, Sun Y, Tang J, Tong K, Zhu J. Noninvasive prenatal testing for assessing foetal sex chromosome aneuploidy: A retrospective study of 45,773 cases. Mol Cytogenet. 2021; 14: 1-8.

47. So PL, Cheng KY, Cheuk KY, Chiu WK, Mak SL, Mok SL, et al. Parental decisions following prenatal diagnosis of sex chromosome aneuploidy in Hong Kong. J Obstet Gynaecol Res. 2017; 43: 18211829.

48. Boyd PA, Loane M, Garne E, Khoshnood B, Dolk H. Sex chromosome trisomies in Europe: Prevalence, prenatal detection and outcome of pregnancy. Eur J Hum Genet. 2011; 19: 231-234.

49. Huete-Garcia A, Otaola-Barranquero M. Demographic assessment of Down syndrome: A systematic review. Int J Environ Res Public Health. 2021; 18: 352.

50. Hanschmidt F, Linde K, Hilbert A, Riedel-Heller SG, Kersting A. Abortion stigma: A systematic review. Perspect Sex Reprod Health. 2016; 48: 169-177.

51. Cartwright AF, Karunaratne M, Barr-Walker J, Johns NE, Upadhyay UD. Identifying national availability of abortion care and distance from major US cities: Systematic online search. J Med Internet Res. 2018; 20: e186. 
52. Botkin JR, Francis LP, Rose NC. Concerns about justification for fetal genome sequencing. Am J Bioeth. 2017; 17: 23-25.

53. Dondorp W, de Wert G, Bombard Y, Bianchi DW, Bergmann C, Borry P, et al. Non-invasive prenatal testing for aneuploidy and beyond: Challenges of responsible innovation in prenatal screening. Eur J Hum Genet. 2015; 23: 1438-1450.

54. Kater-Kuipers A, Bunnik EM, de Beaufort ID, Galjaard RJ. Limits to the scope of non-invasive prenatal testing (NIPT): An analysis of the international ethical framework for prenatal screening and an interview study with Dutch professionals. BMC Pregnancy Childbirth. 2018; 18: 409.

55. Kageleiry A, Samuelson D, Duh MS, Lefebvre P, Campbell J, Skotko BG. Out-of-pocket medical costs and third-party healthcare costs for children with Down syndrome. Am J Med Genet A. 2017; 173: 627-637.

56. Carpinello OJ, Casson PR, Kuo CL, Raj RS, Sills ES, Jones CA. Cost implications for subsequent perinatal outcomes after IVF stratified by number of embryos transferred: A five year analysis of vermont data. Appl Health Econ Health Policy. 2016; 14: 387-395.

57. Goel N, Morris JK, Tucker D, de Walle HE, Bakker MK, Kancherla V, et al. Trisomy 13 and 18prevalence and mortality-A multi-registry population based analysis. Am J Med Genet A. 2019; 179: 2382-2392.

58. Weaver MS, Anderson V, Beck J, Delaney JW, Ellis C, Fletcher S, et al. Interdisciplinary care of children with trisomy 13 and 18. Am J Med Genet A. 2021; 185: 966-977.

59. Reilly CM. Medical professionals as agents of eugenics - abortion counseling for down syndrome. Natl Cathol Bioeth Q. 2018; 18: 237-246.

60. Piepmeier A, Estreich G, Adams R. Unexpected: Parenting, prenatal testing, and down syndrome. New York: NYU Press; 2021.

61. Heyer K. Prenatal testing and disability rights: Challenging "genetic genocide". In: Studies in law, politics, and society bingley. Bingley: Emerald Publishing Limited; 2018. p. 101-129.

62. Nash E, Mohammed L, Cappello O, Naide S. State policy trends 2019: A wave of abortion bans, but some states are fighting back [Internet]. Washington, DC: Guttmacher Institute; 2019 [cited date 2021]. Available from: https://www.guttmacher.org/article/2019/12/state-policy-trends2019-wave-abortion-bans-some-states-are-fighting-back\#.

63. Herzog D. Unlearning eugenics: Sexuality, reproduction, and disability in Post-Nazi Europe. Madison, Wisconsin: University of Wisconsin Press; 2018.

64. Beaty K. To end abortion, don't ban it. Support families instead [Internet]. Kansas City, Missouri: National Catholic Reporter; 2018. Available from: https://www.ncronline.org/news/opinion/end-abortion-dont-ban-it-support-families-instead.

65. State Family planning funding restrictions. Washington, DC: Guttmacher Institute; 2021 [cited date 2021 July 06]. Available from: https://www.guttmacher.org/state-policy/explore/statefamily-planning-funding-restrictions.

66. Stapleton G. Qualifying choice: Ethical reflection on the scope of prenatal screening. Med Health Care Philos. 2017; 20: 195-205.

67. de Jong A, de Wert GM. Prenatal screening: An ethical agenda for the near future. Bioethics. 2015; 29: 46-55.

68. Paul DB. Imagining life with a genetic disorder: The challenge of evaluating health states that exist from birth. OBM Genetics. 2021; 5: 11. 
69. Scott M, Foley KR, Bourke J, Leonard H, Girdler S. "I have a good life": The meaning of well-being from the perspective of young adults with Down syndrome. Disabil Rehabil. 2014; 36: 12901298.

70. Lee A, Knafl K, Van Riper M. Family variables and quality of life in children with Down Syndrome: A scoping review. Int J Environ Res Public Health. 2021; 18: 419.

71. Barter B, Hastings RP, Williams R, Huws JC. Perceptions and discourses relating to genetic testing: Interviews with people with Down syndrome. J Appl Res Intellect Disabil. 2017; 30: 395406.

72. Skotko BG, Levine SP, Goldstein R. Self-perceptions from people with Down syndrome. Am J Med Genet A. 2011; 155A: 2360-2369.

73. Bertrand R. Parents' perspective on having a child with Down Syndrome in France. Am J Med Genet A. 2019; 179: 770-781.

74. Arthur JD, Gupta D. "You can carry the torch now:" A qualitative analysis of parents' experiences caring for a child with trisomy 13 or 18. HEC Forum. 2017; 29: 223-240.

75. Carey JC. Perspectives on the care and management of infants with trisomy 18 and trisomy $13:$ Striving for balance. Curr Opin Pediatr. 2012; 24: 672-678.

76. Lebedoff AN, Carey JC. Parent-reported histories of adults with trisomy 13 syndrome. Am J Med Genet A. 2021; 185: 1743-1756.

77. Carey JC. Emerging evidence that medical and surgical interventions improve the survival and outcome in the trisomy 13 and 18 syndromes. Am J Med Genet A. 2020; 182: 13-14.

78. Turriff A, Macnamara E, Levy HP, Biesecker B. The impact of living with Klinefelter syndrome: A qualitative exploration of adolescents and adults. J Genet Couns. 2017; 26: 728-737.

79. Otter M, Schrander-Stumpel CT, Curfs LM. Triple X syndrome: A review of the literature. Eur J Hum Genet. 2010; 18: 265-271.

80. Gravholt $\mathrm{CH}$, Tartaglia N, Disteche C. Sex chromosome aneuploidies in 2020-the state of care and research in the world. Am J Med Genet C Semin Med Genet. 2020; 184: 197-201.

81. Thompson T, Zieba B, Howell S, Karakash W, Davis S. A mixed methods study of physical activity and quality of life in adolescents with Turner syndrome. Am J Med Genet A. 2020; 182: 386-396.

82. Boardman FK, Hale R. How do genetically disabled adults view selective reproduction? Impairment, identity, and genetic screening. Mol Genet Genomic Med. 2018; 6: 941-956.

83. McNeill A, Lewis R, Freeth M. Views of adults with 22q11 deletion syndrome on reproductive choices. Am J Med Genet A. 2020; 182: 1284-1287.

84. Dukhovny S, Norton ME. What are the goals of prenatal genetic testing? Semin Perinatol. 2018; 42: 270-274.

85. Bowman-Smart H, Savulescu J, Mand C, Gyngell C, Pertile MD, Lewis S, et al. 'Small cost to pay for peace of mind': Women's experiences with non-invasive prenatal testing. Aust N Z J Obstet Gynaecol. 2019; 59: 649-655.

86. Di Mattei V, Ferrari F, Perego G, Tobia V, Mauro F, Candiani M. Decision-making factors in prenatal testing: A systematic review. Health Psychol Open. 2021; 8: 2055102920987455.

87. Löwy I. Non-invasive prenatal testing: A diagnostic innovation shaped by commercial interests and the regulation conundrum. Soc Sci Med. 2020; 113064. doi: 10.1016/j.socscimed.2020.113064.

88. Thomas GM, Rothman BK, Strange H, Latimer JE. Testing times: The social life of non-invasive prenatal testing. Sci Technol Soc. 2021; 26: 81-97. 
89. Newswire P. Global NIPT market (2020 to 2030) - analysis and forecast [Internet]. Chicago, United States: Cision; 2020 [2021 July 06]. Available from: https://www.prnewswire.com/newsreleases/global-nipt-market-2020-to-2030---analysis-and-forecast-301154067.html.

90. Estreich G. Fables and futures: Biotechnology, disability, and the stories we tell ourselves. Cambridge, Massachusetts: MIT Press; 2019.

91. Michie M. Is preparation a good reason for prenatal genetic testing? Ethical and critical questions. Birth Defects Res. 2020; 112: 332-338.

92. Hurford E, Hawkins A, Hudgins L, Taylor J. The decision to continue a pregnancy affected by Down syndrome: Timing of decision and satisfaction with receiving a prenatal diagnosis. J Genet Couns. 2013; 22: 587-593.

93. McCormick A, Simpson P, Pan A, McIntosh J, Hibbard J. Fetal anomalies and labor complications [36K]. Obstet Gynecol. 2017; 129: 121S.

94. Massalska D, Bijok J, Kucinska-Chahwan A, Zimowski JG, Ozdarska K, Raniszewska A, et al. Maternal complications in molecularly confirmed diandric and digynic triploid pregnancies: Single institution experience and literature review. Arch Gynecol Obstet. 2020; 301: 1139-1145.

95. Ergaz-Shaltiel Z, Engel O, Erlichman I, Naveh Y, Schimmel MS, Tenenbaum A. Neonatal characteristics and perinatal complications in neonates with Down syndrome. Am J Med Genet A. 2017 ; 173: 1279-1286.

96. Seither K, Tabbah S, Tadesse DG, Suhrie KR. Neonatal complications of Down syndrome and factors necessitating intensive care. Am J Med Genet A. 2021; 185: 336-343.

97. Resta RG. The DNA Excange [Internet]. WordPress; 2015 [cited date 2021]. Available from: https://thednaexchange.com/2015/09/21/1193-to-4/.

98. de Koning MA, Haak MC, van Scheltema PN, Peeters-Scholte C, Koopmann TT, Nibbeling EA, et al. From diagnostic yield to clinical impact: A pilot study on the implementation of prenatal exome sequencing in routine care. Genet Med. 2019; 21: 2303-2310.

99. Tolusso LK, Hazelton P, Wong B, Swarr DT. Beyond diagnostic yield: Prenatal exome sequencing results in maternal, neonatal, and familial clinical management changes. Genet Med. 2021; 23: 909-917.

100.Pratt M, Garritty C, Thuku M, Esmaeilisaraji L, Hamel C, Hartley T, et al. Application of exome sequencing for prenatal diagnosis: A rapid scoping review. Genet Med. 2020; 22: 1925-1934.

101.Deden C, Neveling K, Zafeiropopoulou D, Gilissen C, Pfundt R, Rinne T, et al. Rapid whole exome sequencing in pregnancies to identify the underlying genetic cause in fetuses with congenital anomalies detected by ultrasound imaging. Prenat Diagn. 2020; 40: 972-983.

102. Werner-Lin A, McCoyd JL, Bernhardt BA. Actions and uncertainty: How prenatally diagnosed variants of uncertain significance become actionable. Hastings Cent Rep. 2019; 49: S61-S71.

103. Ivry T. The predicaments of koshering prenatal diagnosis and the rise of a new rabbinic leadership. Ethnol Fr. 2015; 45: 281-292.

104. Dive L, Newson AJ. Reproductive carrier screening: Responding to the eugenics critique. J Med Ethics. 2021. doi: 10.1136/medethics-2021-107343. 


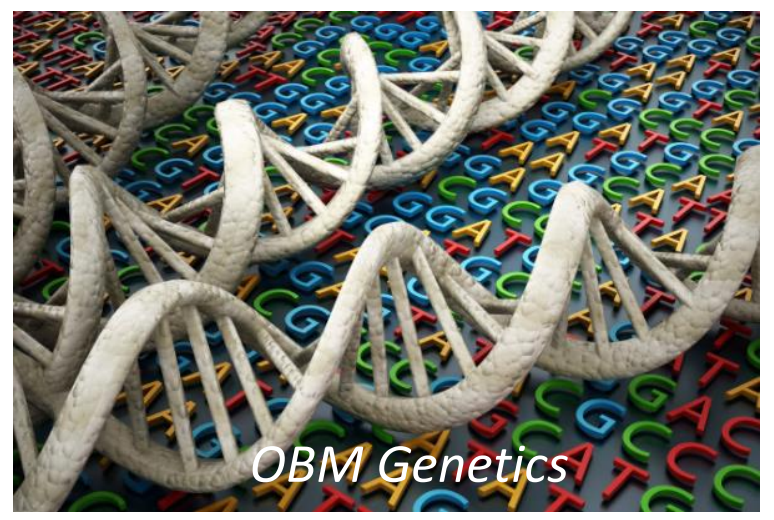

Enjoy OBM Genetics by:

1. Submitting a manuscript

2. Joining in volunteer reviewer bank

3. Joining Editorial Board

4. Guest editing a special issue

For more details, please visit:

http://www.lidsen.com/journals/genetics 